\title{
Stability of plasmonic metal nanoparticles integrated in the back contact of ultra-thin $\mathrm{Cu}(\mathrm{In}, \mathrm{Ga}) \mathrm{S}_{2}$ solar cells
}

\author{
M. Schmid ${ }^{\mathrm{a}}$, J. Klaer ${ }^{\mathrm{b}}$, R. Klenk ${ }^{\mathrm{a}}$, M. Topič ${ }^{\mathrm{c}}$, J. Krčc \\ ${ }^{a}$ Helmholtz Zentrum Berlin, Heterogeneous Material Systems, Hahn-Meitner-Platz 1, \\ 14109 Berlin, Germany \\ ${ }^{b}$ Helmholtz Zentrum Berlin, Technology, Hahn-Meitner-Platz 1, 14109 Berlin, Germany \\ ${ }^{c}$ University of Ljubljana, Faculty of Electrical Engineering, Tržaška 25, 1000 Ljubljana, \\ Slovenia
}

\begin{abstract}
Ultra-thin solar cells on transparent back contacts constitute the basis for highly efficient tandem solar devices which can surpass the single cell efficiency limit. The material reduction related to ultra-thin high efficiency devices additionally lowers the price. Despite the fact they are ultra-thin the absorbers still have to remain optically thick and therefore require adequate light management. A promising approach for enhanced absorption is plasmonic scattering from metal nanoparticles. In this paper we discuss the experimental incorporation of Ag nanoparticles in ultra-thin wide-gap chalcopyrite solar cells on transparent back contacts. A $6.9 \%$ efficient $500 \mathrm{~nm}$ $\mathrm{Cu}(\mathrm{In}, \mathrm{Ga}) \mathrm{S}_{2}$ solar cell on $\mathrm{In}_{2} \mathrm{O}_{3}$ :Mo (at this point without nanoparticles) is the starting point. For the predicted optimum design of including particles at the rear side the stability of the nanostructures integrated in the back contact is investigated in detail. As a first step towards proof-of-concept, absorption enhancement from the nanoparticles included in the complete solar
\end{abstract}

Email address: martina.schmid@helmholtz-berlin.de (M. Schmid ) 
cell is experimentally shown in optical properties.

Keywords: tandem solar cell, ultra-thin $\mathrm{Cu}(\mathrm{In}, \mathrm{Ga}) \mathrm{S}_{2}$, plasmonic absorption enhancement, transparent back contact, stability of metal nanoparticles

\section{Introduction}

Photovoltaics have a high potential to contribute significantly to renewable energy supplies. To become more competitive two major technical aspects have to be addressed: increased efficiency of the cells and reduced material consumption. Both can contribute to lower costs of thin-film PV modules per megawatt peak. The only concept realized so far which exceeds the Shockley-Queisser single cell efficiency limit is the tandem solar cell [1]. An adequate design includes a thin top cell allowing the transmittance of sufficient light to the bottom cell [2]. In this way, additional to the expected efficiency enhancement, low material consumption is provided. Yet, despite the high transmittance below the band-gap desirable for the top cell its absorption above-gap has to be kept up. Therefore, means of wavelength selective absorption enhancement are required.

Plasmonic light trapping offers exactly this wavelength selective absorption enhancement. At the wavelength of the plasmon resonance the excited nanostructures show maxium scattering which is characterized by being preferentially directed to the material with the higher refractive index and into angles higher than the one of total reflection, e.g. into trapped modes [3]. Additionally, an enhanced near-field and coupling into surface plasmon-polaritons may be observed [4]. Plasmonic absorption enhancement 
from metal nanoparticles has been studied with GaAs [5], silicon $[6,7,8]$, organic [9] and dye-sensitized solar cells [10]. In this paper we experimentally investigate the application of the concept to chalcopyrite solar cells on transparent back contacts. A main challenge of integrating metal nanoparticles in the rear of a chalcopyrite solar cell is the nanoparticles' stability with the high temperature absorber process, which we will investigate in detail.

\section{Background}

Chalcopyrites, being direct semiconductors, can reach absorption coefficients of $10^{5} 1 / \mathrm{cm}$. Despite the standard absorber thickness being approx. $2 \mu \mathrm{m}$, an almost complete absorption is still achieved with a $1 \mu \mathrm{m}$ thick absorber given this absorption coefficient. To observe a significant drop in absorption, the chalcopyrite thickness has to be reduced drastically. This comes along with experimental challenges of solar cell fabrication and thus there are few publications on ultra-thin chalopyrite solar cells [11]. On the other hand the possible drastic decrease in absorber layer thickness allows for a crucial reduction of material consumption and also a possible increase in sub-gap transparency of an IR-transparent solar cell for tandem applications.

For compensating absorption losses in ultra-thin devices, nanostructures for selective absorption enhancement are desirable. In [3] the optimum design of an IR-transparent $\mathrm{CuGaSe}_{2}$ solar cell (top component of tandem) including metal nanoparticles for plasmonic absorption enhancement has been derived using our extended optical model which combines plasmonic scattering with thin-film optics. The principle stack based on a $200 \mathrm{~nm}$ thin absorber layer and promising absorption enhancement when including silver nanopar- 

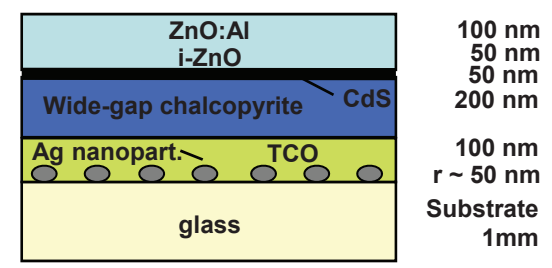

Figure 1: Structure of a wide-gap chalcopyrite solar cell on a transparent back contact (with a thin absorber layer) provides promising absorption enhancement with the integration of Ag nanoparticles.

ticles is shown in Fig. 1. The particles of a radius $\gtrsim 50 \mathrm{~nm}$ are included at the rear side of the solar cell. The absorber material $\mathrm{CuGaSe}_{2}$ previously used in the simulations, is however characterized by a material-related efficiency limit that presently cannot be lifted over the $10 \%$ mark [12]. By adding In, increasing device efficiencies are obtained; in order to maintain a high band-gap - desirable for the top cell of a tandem - Se has to be replaced by S. Wide-gap chalcopyrite solar cells with $E_{\mathrm{g}}=1.53 \mathrm{eV}$ and $\eta=12.9 \%$ can be achieved on a molybdenum back contact [13] (no nanoparticles included). On transparent back contacts these solar cells can reach $8.1 \%$ with standard absorber thicknesses $(2 \mu \mathrm{m})$ [14]. For reduced absorber layer thickness we could show $6.9 \%$ efficiency for $500 \mathrm{~nm} \mathrm{Cu}(\mathrm{In}, \mathrm{Ga}) \mathrm{S}_{2}$ on $\mathrm{In}_{2} \mathrm{O}_{3}: \mathrm{Mo}$ as presented in this paper(firstly without nanoparticles). The efficiency is related to an open circuit voltage $V_{\mathrm{OC}}=801 \mathrm{mV}$, a short circuit current density $j_{\mathrm{SC}}$ $=17.1 \mathrm{~mA} / \mathrm{cm}^{2}$ and a fill factor $F F=50.6 \%$.

Thus, in our investigations for enhanced absorption from metal nanoparticles in IR-transparent chalcopyrite solar cell $\mathrm{CuGaSe}_{2}$ was replaced by $\mathrm{Cu}(\mathrm{In}, \mathrm{Ga}) \mathrm{S}_{2}$. The transparent back contact is now made of $\mathrm{In}_{2} \mathrm{O}_{3}$ :Mo which 
shows optical and electrical properties comparable to those of $\mathrm{SnO}_{2}: \mathrm{F}$ or $\mathrm{ZnO}$ but which induces no contamination by diffusion of impurities and is available in-house with arbitrary thickness. It was derived in [3] that the Ag nanoparticles are best introduced at the rear side of the solar cell. In comparison to the front side this position avoids losses of short-wavelength light due to parasitic absorption in the nanoparticles before the light enters the absorber layer. By inserting the nanoparticles underneath the back TCO (transparent conductive oxide) direct diffusion of metallic silver into the absorber is expected to be prevented. However, the fabrication of a chalcopyrite absorber usually requires a high temperature step. The stability of the metal nanoparticles with this step is a critical issue. Therefore, a main focus in this paper is the investigation of the persistence of Ag nanoparticles with rapid thermal processing. In the following we will discuss their integration in wide-gap $\mathrm{Cu}(\mathrm{In}, \mathrm{Ga}) \mathrm{S}_{2}$ solar cells with the purpose of absorption enhancement.

\section{Experimental details}

The $\mathrm{Cu}(\mathrm{In}, \mathrm{Ga}) \mathrm{S}_{2}$ absorber is prepared by sulfurization of a sputtered precursor of $\mathrm{Cu}$, In and Ga. The formation of the polycrystalline layer is achieved by rapid thermal processing (RTP) $[15,16]$. The according sequential process had a maximum temperature of $630{ }^{\circ} \mathrm{C}$ held for 2 minutes in our case. The layer thickness was chosen to be as low as $\sim 500$ and $\sim 250 \mathrm{~nm}$, e.g. 4 and 8 times thinner than standard absorbers. The p-n-junction with the $\mathrm{Cu}(\mathrm{In}, \mathrm{Ga}) \mathrm{S}_{2}$ is formed by adding $50 \mathrm{~nm}$ of chemical bath deposited CdS, $50 \mathrm{~nm}$ of intrinsic and $100 \mathrm{~nm}$ of n-doped sputtered $\mathrm{ZnO}$. As transparent 
back contact we used $\mathrm{In}_{2} \mathrm{O}_{3}$ :Mo with a thickness of 100 - $200 \mathrm{~nm}$ sputtered onto soda-lime glass. Ag nanoparticles were prepared by evaporation of a thin metal film (12 - $18 \mathrm{~nm}$ for the samples presented here) and subsequent thermal annealing at $200{ }^{\circ} \mathrm{C}$ for one hour.

Optical measurements (transmission and reflection) were carried out using an UV-Vis photospectrometer with an integrating sphere. A scanning electron microscope (SEM) including an EDX (energy dispersive X-ray spectroscopy) add-on served for structural investigations (operating voltage $7 \mathrm{kV}$ compared to $3 \mathrm{kV}$ for SEM). For better electrostatic stability during EDX mapping a second set of samples was prepared on silicon instead of glass. Resistivity measurements were conducted using a four-point probe.

\section{Results}

\subsection{Stability of nanoparticles with RTP}

As motivated above, the Ag nanoparticles are to be integrated at the rear side of the glass $/ \mathrm{In}_{2} \mathrm{O}_{3}: \mathrm{Mo} / \mathrm{Cu}(\mathrm{In}, \mathrm{Ga}) \mathrm{S}_{2} / \mathrm{CdS} / \mathrm{i}-\mathrm{ZnO} / \mathrm{n}-\mathrm{ZnO}$ solar cell, i. e. at the glass $/ \mathrm{In}_{2} \mathrm{O}_{3}$ :Mo interface. Silver was chosen as the material for the particles because of high scattering efficiency compared to other metals like gold or copper [17]. In addition, compared to these materials silver is expected to show less interdiffusion with the $\mathrm{Cu}(\mathrm{In}, \mathrm{Ga}) \mathrm{S}_{2}$ absorber. Nevertheless, the separation of the nanoparticles and the absorber layer by a thin TCO layer is desireable to avoid any intermixing. Still the stability of the particles with the high temperature RTP step has to be proven. With such high temperatures a dissolution of the particles and diffusion into the $\operatorname{In}_{2} \mathrm{O}_{3}: \mathrm{Mo}$

might occur. If so, the effect of plasmonic scattering from nanoparticles could 
(a)

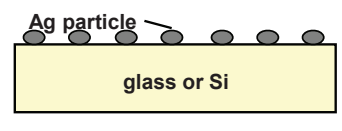

(b)

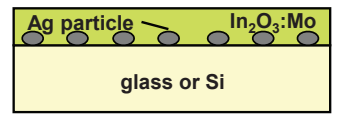

$\downarrow \downarrow$ RTP heating $\downarrow \quad \downarrow$ Ag particle $\mathrm{O} \mathrm{O}^{\ln _{2} \mathrm{O}_{3}: \mathrm{Mo}}$

glass or $\mathrm{Si}$ (c)

Figure 2: Structures for stability investigations of (a) Ag nanoparticles on substrate, which were (b) covered by $\mathrm{In}_{2} \mathrm{O}_{3}$ :Mo and (c) additionally subject to rapid thermal processing.

be destroyed and maybe even the absorber layer altered by further diffusion of the $\mathrm{Ag}$ into the $\mathrm{Cu}(\mathrm{In}, \mathrm{Ga}) \mathrm{S}_{2}$. In order to exclude these possibilities the following samples were fabricated and investigated (see Fig. 2): Ag nanoparticles with a radius of approx. $50 \mathrm{~nm}$ were prepared on soda-lime glass (a) and coated with $\mathrm{In}_{2} \mathrm{O}_{3}:$ Mo (b) before subject to the high temperature RTP step (c).

Fig. 3 shows the reflection measured from these samples. For the bare nanoparticles on glass substrate (Fig. 2(a)) the main peak of the plasmon resonance is observed at $480 \mathrm{~nm}$ in the reflection, see the black curve in Fig. 3. Compared to the resonance wavelength of Ag nanoparticles in air which is at $350 \mathrm{~nm}$ [18] it is red-shifted due to glass having a higher refractive index than air. A second smaller resonance is observed which is a result of the ellipsoidal shape of the particles in the plane of the interface. When the nanoparticles are overcoated with $\mathrm{In}_{2} \mathrm{O}_{3}$ :Mo the resonance peak is further red-shifted because of the even higher refractive index of the surrounding. The resonance wavelength is then found at $700 \mathrm{~nm}$ (green curve) for these nanoparticles obtained from an $18 \mathrm{~nm} \mathrm{Ag} \mathrm{film.} \mathrm{With} \mathrm{rapid} \mathrm{thermal} \mathrm{processing} \mathrm{the} \mathrm{reflection}$ of the sample does not show any significant changes. Especially the main resonance peak, its position and shape are very well preserved (red curve in 


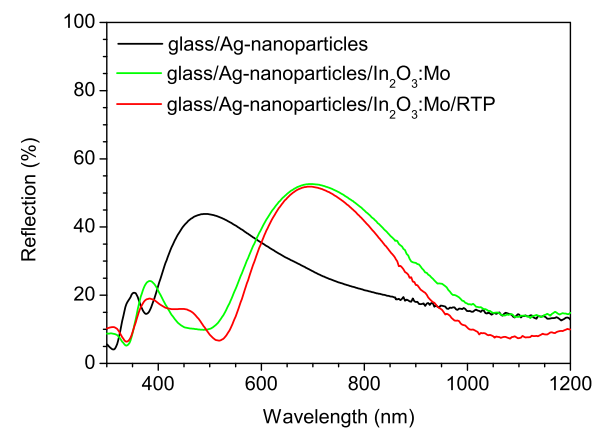

Figure 3: Optical reflection of Ag nanoparticles on glass substrate (black line), covered with $\mathrm{In}_{2} \mathrm{O}_{3}$ :Mo (green / light grey line) and additionally subject to rapid thermal processing (red / dark grey line).

Fig. 3). Around the second smaller resonance slight deviations occur. It was observed also for other samples of $\mathrm{Ag}$ nanoparticles on $\mathrm{In}_{2} \mathrm{O}_{3}$ :Mo that this second resonance may appear as a distinct reflection peak or as a shoulder. This is attributed to the background of the $\mathrm{In}_{2} \mathrm{O}_{3}$ :Mo which shows a reflection minimum at $400 \mathrm{~nm}$. Minor changes in reflection in the form of small variations in peak broadness as they occure in Fig. 3 may interfere differently with the background reflection minimum and therefore once result in a peak, the other time in a shoulder. Nevertheless, despite minor deviations found at off-resonance positions, the major characterisitics of the plasmon resonance persist. This observation is an indication of the stability of the $\mathrm{Ag}$ nanoparticles underneath $\mathrm{In}_{2} \mathrm{O}_{3}$ :Mo during a high temperature RTP step.

Furthermore, the samples were structurally investigated using an SEM with an attached EDX unit. Fig. 4 (a) and (b) show SEM images of Ag nanoparticles on glass and (also on glass) Ag nanoparticles overcoated with $\mathrm{In}_{2} \mathrm{O}_{3}: \mathrm{Mo}$, respectively. The crystallinity of the $\mathrm{In}_{2} \mathrm{O}_{3}:$ Mo grains growing 
on the metal nanoparticles is visible in (b). The pictures illustrate that the nanoparticles constitute centers of favored TCO growth. The shapes imposed by the nanoparticles are taken over by the thin $\mathrm{In}_{2} \mathrm{O}_{3}$ :Mo film. There are differences in contrast between (a) and (b) due to the opposite charging of glass and TCO. In Fig. 4 (c) and (d) the Ag nanoparticles coated with $\mathrm{In}_{2} \mathrm{O}_{3}$ :Mo are imaged before and after RTP, respectively. Here, virtually no differences are obvious. Thus, the shape of the nanoparticles is preserved through the TCO layer and it equally persists after RTP. The thin Ag films in Fig. 4 (e) which were used for particle formation via thermal treatment show a completely different surface morphology when overcoated with $\mathrm{In}_{2} \mathrm{O}_{3}$ :Mo, see Fig. 4 (f), compared to the case of Ag nanoparticles (Fig. 4 (b)-(c)). This is another clear indication that the nanoparticles persist underneath the $\operatorname{In}_{2} \mathrm{O}_{3}$ :Mo during rapid thermal processing and that there is no flattening of the nanoparticles towards the case of a flat $\mathrm{Ag}$ film and a resulting different $\mathrm{In}_{2} \mathrm{O}_{3}$ :Mo arrangement. Thus, from the top SEM views the stability of nanoparticles with RTP appears to be asserted. The sheet resistance of $\mathrm{In}_{2} \mathrm{O}_{3}$ : Mo grown on a Ag thin film is comparable to that of the bare $\mathrm{In}_{2} \mathrm{O}_{3}:$ Mo. For $\mathrm{In}_{2} \mathrm{O}_{3}:$ Mo on $\mathrm{Ag}$ nanoparticles it is a factor 2-3 higher, which is still within range to be used as a back contact. The increased resistivity is in agreement with general findings of TCO growth on rough substrates [19]. The acceptable sheet resistance is an indication that still a closed $\operatorname{In}_{2} \mathrm{O}_{3}$ :Mo film is formed which is also visible when recording the SEM pictures.

For final stability proof $\mathrm{Ag}$ nanoparticles overcoated with $\mathrm{In}_{2} \mathrm{O}_{3}$ :Mo and before and after rapid thermal processing, respectively, were imaged in the cross section and EDX mappings were performed. In this case Si was used as 
a substrate to avoid drifting of the imaged position during the spectroscopy measurements. When imaging non- or lowly conductive materials with the electron beam heavy electrostatic charging occurs which not only leads to bad contrast but also to shifts in the imaged position. These effects are reduced by inserting a good conductor like e.g. the silicon substrate. The results of the EDX mappings are shown in Fig. 5. Ag is represented in purple (light grey) in the maps, whereas red (dark grey) stands for In characterizing the $\operatorname{In}_{2} \mathrm{O}_{3}$ :Mo. In Fig. 5 (a) and (b) the Ag signal is shown before and after RTP, respectively. Circles are drawn to guide the eye to the nanoparticles. Ag clustering occurs both before and after rapid thermal processing, highlighting that the particles persist. Fig. 5 (c) and (d) represent the pictures of the Ag nanoparticles embedded in the $\mathrm{In}_{2} \mathrm{O}_{3}$ :Mo. Particles overcoated by the TCO are identifiable both before (c) and after (d) the high temperature RTP step. Together with the SEM top views and the results of the optical measurements the stability with RTP of Ag nanoparticles underneath $\operatorname{In}_{2} \mathrm{O}_{3}$ :Mo is considered to be confirmed. The particle shape and the specific resonance persist. No significant diffusion of $\mathrm{Ag}$ leading to the dissappearence of the nanoparticles can be expected from this.

Beyond the accuray of EDX still a diffusion of $\mathrm{Ag}$ through the $\operatorname{In}_{2} \mathrm{O}_{3}: \mathrm{Mo}$ and into the absorber layer might occur, which we will roughly estimate in the following. There is no specific literature data on $\mathrm{Ag}$ diffusion in $\operatorname{In}_{2} \mathrm{O}_{3}$ :Mo, but in general activation energies $Q$ for $\mathrm{Ag}$ in semiconductors like $\mathrm{Si}$, Ge or $\mathrm{ZnSe}$ are in the range of $1 \mathrm{eV}$ at approx. $600^{\circ} \mathrm{C}$ [20]. For a given $\mathrm{In}_{2} \mathrm{O}_{3}: \mathrm{Mo}$ thickness of $100 \mathrm{~nm}$ and a high temperature step on the order of $10^{2} \mathrm{~s}$ a diffusion of $D>10^{-12} \mathrm{~cm}^{2} / \mathrm{s}$ was required so that Ag would penetrate the 
(a)

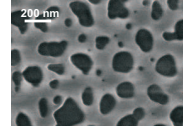

(b)

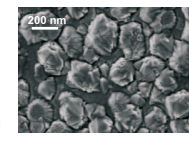

(c)

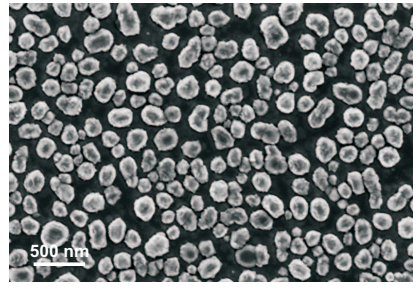

(d)

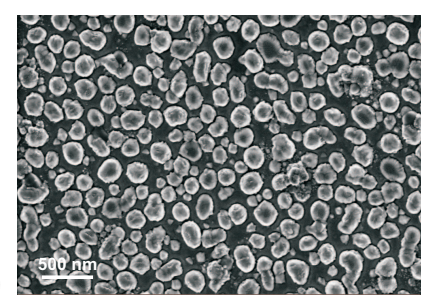

(e)

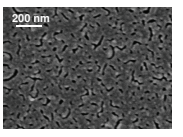

(f)

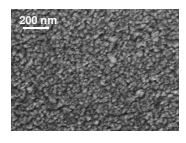

Figure 4: SEM top view of Ag nanoparticles (a) on glass substrate and (b) covered with $200 \mathrm{~nm} \mathrm{In}_{2} \mathrm{O}_{3}: \mathrm{Mo}$, (c) before, (d) after rapid thermal processing; references of (e) thin $\mathrm{Ag}$ film before thermal particle formation and (f) thin Ag film coated with $\operatorname{In}_{2} \mathrm{O}_{3}$ :Mo.

TCO layer. Based on the diffusion formula $D=D_{0} \exp (-Q / k T)$, and using $Q=1 \mathrm{eV}$ and $T=1000 \mathrm{~K}$, the diffusivity $D_{0}$ then needed to be of an order of magnitude bigger than $10^{-7} \mathrm{~cm}^{2} / \mathrm{s}$. This value is not out of reach for data found in literature which may vary between $10^{-2}$ and $10^{-11}[20]$. For an oxide like $\mathrm{SiO}_{2}$, however, it was published to be of the order of $10^{-8}$ [21]. In this particular case of oxide there would be no diffusion of $\mathrm{Ag}$ through a 100 $\mathrm{nm}$ layer within $10^{2} \mathrm{~s}$. In any case the diffusivity will strongly depend on the crystallinity of the material to penetrate [22]. However, even if there is a minor diffusion of $\mathrm{Ag}$ into $\mathrm{Cu}(\mathrm{In}, \mathrm{Ga}) \mathrm{S}_{2}$ it is not expected to be detrimental since it constitutes an isovalent substitute in the chalcopyrite structure [23]. The main fact is, that the nanoparticles and their plasmonic behavior persist after the high temperature processing. 
(a)

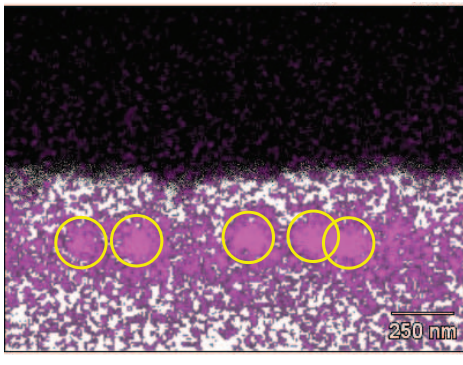

(c)

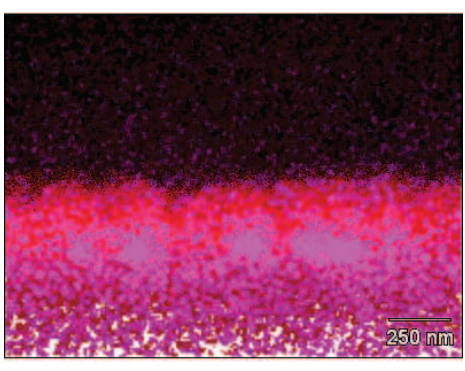

(b)

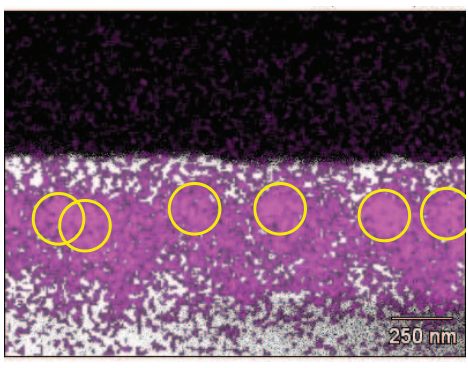

(d)

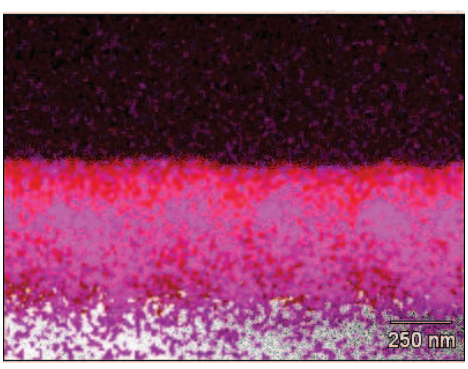

Figure 5: EDX mappings of cross sections of Ag nanoparticles (on Si substrate) covered by $200 \mathrm{~nm} \mathrm{In}_{2} \mathrm{O}_{3}$ :Mo (a), (c) before and (b), (d) after rapid thermal processing. (a) and (b) show the mapping results of $\mathrm{Ag}$ with circles guiding the eye to the nanoparticles. In (c) and (d) they are depicted embedded in In (red / dark grey color compared to purple / light grey for Ag). 


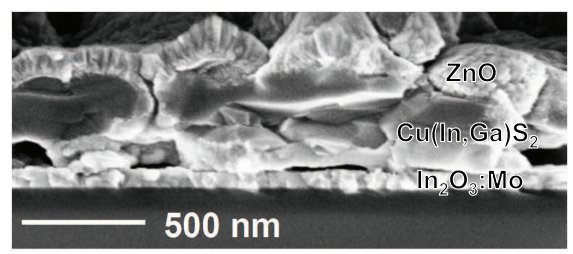

Figure 6: SEM cross sectional view of a glass $/ \mathrm{In}_{2} \mathrm{O}_{3}: \mathrm{Mo} \mathrm{Cu}(\mathrm{In}, \mathrm{Ga}) \mathrm{S}_{2} / \mathrm{CdS} / \mathrm{i}-\mathrm{ZnO} / \mathrm{n}-\mathrm{ZnO}$ solar cell with the absorber thickness reduced to one fourth of the standard value.

\subsection{Ag nanoparticles in ultra-thin $\mathrm{Cu}(\mathrm{In}, \mathrm{Ga}) \mathrm{S}_{2}$ solar cells}

After the proof of the stability of $\mathrm{Ag}$ nanoparticles underneath $\operatorname{In}_{2} \mathrm{O}_{3}: \mathrm{Mo}$ during a high temperature step, (IR-transparent) $\mathrm{Cu}(\mathrm{In}, \mathrm{Ga}) \mathrm{S}_{2}$ solar cells were deposited on top of the $\operatorname{In}_{2} \mathrm{O}_{3}$ :Mo. As motivated above, the thickness of the absorber layer was significantly reduced to approx. $500 \mathrm{~nm}$ and furthermore to $250 \mathrm{~nm}$. An SEM cross section image of a $500 \mathrm{~nm} \mathrm{Cu}(\mathrm{In}, \mathrm{Ga}) \mathrm{S}_{2}$ solar cell is shown in Fig. 6. Reasonably large sized grains are visible covering the TCO back contact in a loose manner as typical for $\mathrm{Cu}(\mathrm{In}, \mathrm{Ga}) \mathrm{S}_{2}$. The $\mathrm{In}_{2} \mathrm{O}_{3}$ :Mo layer has a thickness of $100 \mathrm{~nm}$ here as does the $\mathrm{n}-\mathrm{ZnO}$ which forms the front contact with CdS and i-ZnO (in sum approx. $200 \mathrm{~nm}$ ). The solar cell with approx. $250 \mathrm{~nm} \mathrm{Cu}(\mathrm{In}, \mathrm{Ga}) \mathrm{S}_{2}$ absorber thickness shows a similar cross sectional view (not shown here).

For the glass $/ \mathrm{In}_{2} \mathrm{O}_{3}: \mathrm{Mo} /(250 \mathrm{~nm}) \mathrm{Cu}(\mathrm{In}, \mathrm{Ga}) \mathrm{S}_{2} / \mathrm{CdS} / \mathrm{i}-\mathrm{ZnO} / \mathrm{n}-\mathrm{ZnO}$ solar cell the impact of Ag nanoparticles incorporated at the rear side is presented in Fig. 7 (a). The absorption $A$ is shown for the case with (green / light grey line) and without (black line) Ag nanoparticles integrated underneath the $\mathrm{In}_{2} \mathrm{O}_{3}$ :Mo. The absorption was calculated from measurements of transmission $T$ and reflection $R$ as $A=100 \%-T-R$. Despite the reduction of the 
absorber layer thickness to one eighth of the standard value the absorption still reaches a maximum of over 90\%. Only above a wavelength of $500 \mathrm{~nm}$ it starts to drop below the $90 \%$ mark, going down to around $75 \%$ at the band-gap for the case without nanoparticles. But exactly here a clear absorption enhancement is found with the integration of Ag nanoparticles. The enhancement occurs around 600 - $700 \mathrm{~nm}$. The resonance wavelength of the $\mathrm{Ag}$ nanoparticles covered with $\mathrm{In}_{2} \mathrm{O}_{3}$ : Mo was adjusted to this value close to the band gap by choosing the adequate size of nanoparticles. Due to their ellipsoidal shape there is a distinct dependance of the resonance wavelength on the particle volume. Ag nanoparticles of medium radii slightly larger than $50 \mathrm{~nm}$ showed the best performance. Smaller particles tend to have a resonance at $<500 \mathrm{~nm}$, whereas bigger ones show a very broad resonance peak. The absorption enhancement in Fig. 7(a) is only observed above the band-gap energy, whereas below gap the absorption appears reduced. These optical data express the enhancement which is expected with the integration of metal nanoparticles in a thin IR-transparent wide-gap chalcopyrite solar cell. Additonally, the absorption data need to be compared to the transparency. For tandem application not only a sufficient above-gap absorption has to be ensured, but also the sub-gap transparency has to be as high as possible. The introduction of absorption enhancing nanostructures may only show its fortifying influence in the above-gap region, the transparency below gap is aimed at being increased by the reduced absorber layer thickness. Fig. 7 (b) gives in green / light grey the transparency of the ultra-thin glass $/ \mathrm{In}_{2} \mathrm{O}_{3}: \mathrm{Mo} / \mathrm{CuGaSe}_{2} / \mathrm{CdS} / \mathrm{i}-\mathrm{ZnO} / \mathrm{n}-\mathrm{ZnO}$ solar cell with 250 $\mathrm{nm}$ absorber thickness and integrated Ag nanoparticles in between the glass 
and the back TCO. Compared to the reference without particles in black the tranparency below gap is very similar, even slightly decreased, strengthening the applicabilty in the tandem device. Above gap a loss in transparency occurs which coincides with the increased absorption (the reflection of both samples being very comparable). The effect of reduced absorber thickness on sub-gap transparency becomes obvious when comparing to the sample with $500 \mathrm{~nm}$ absorber layer thickness, shown in red / dark grey in the graph. There is a significant improvement confirming that this approach is indeed promising for building a most efficient tandem device.

\section{Discussion and outlook}

The absorption enhancement by integration of $\mathrm{Ag}$ nanoparticles at the rear side of ultra-thin IR-transparent $\mathrm{Cu}(\mathrm{In}, \mathrm{Ga}) \mathrm{S}_{2}$ solar cells was found in optical measurements. However, from these measurements one cannot exclude possible parasitic absorptance in the metal nanoparticles themselves and extract an increase in the absorptance in the $\mathrm{Cu}(\mathrm{In}, \mathrm{Ga}) \mathrm{S}_{2}$ absorber. The proof of electrical absorption enhancement has to follow. Measurements of quantum efficiencies of samples with and without nanoparticles will depict the absorption convertible to electric current and thus distinguish usable absorption from parasitic absorption in the particles. But the fabrication of ultra-thin $\mathrm{Cu}(\mathrm{In}, \mathrm{Ga}) \mathrm{S}_{2}$ devices is a challenging task. For example in the experiments with the $\sim 250 \mathrm{~nm}$ thin absorber layer we could not obtain any electrically working device using a transparent back contact so far - no matter if with or without integration of Ag. Yet, the electrical results shown for the $500 \mathrm{~nm} \mathrm{Cu}(\mathrm{In}, \mathrm{Ga}) \mathrm{S}_{2}$ solar cell in section 2 point out the high potential 


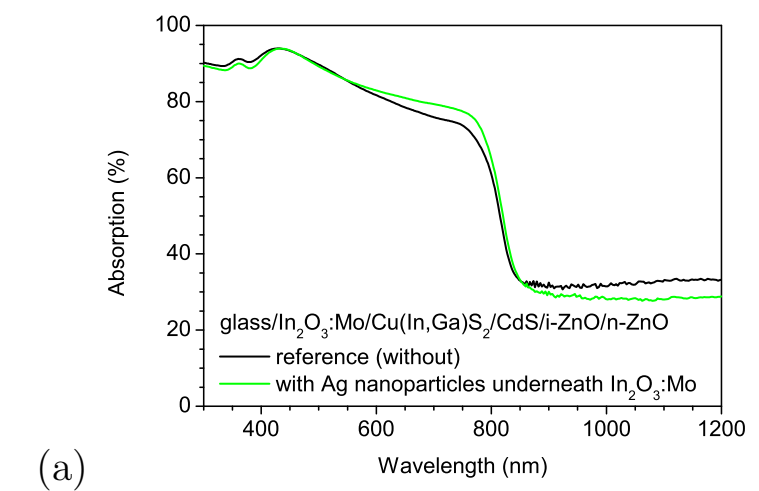

(a)

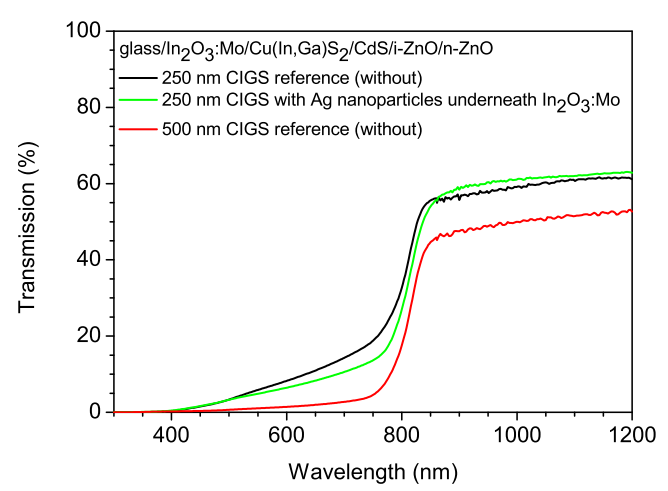

Figure 7: (a) Optical absorption of a glass $/ \operatorname{In}_{2} \mathrm{O}_{3}: \mathrm{Mo} /(250 \mathrm{~nm}) \mathrm{Cu}(\mathrm{In}, \mathrm{Ga}) \mathrm{S}_{2} / \mathrm{CdS} / \mathrm{i}-$ $\mathrm{ZnO} / \mathrm{n}-\mathrm{ZnO}$ solar cell with $\mathrm{Ag}$ nanoparticles included at the rear side (underneath $\mathrm{In}_{2} \mathrm{O}_{3}: \mathrm{Mo}$ ) (in green / light grey) compared to the reference without nanoparticles (in black). (b) Corresponding transmission of the samples in (a) and additional $500 \mathrm{~nm}$ $\mathrm{Cu}(\mathrm{In}, \mathrm{Ga}) \mathrm{S}_{2}$ device without nanoparticles shown in red / dark grey. 
of these devices and give the basis for further development and enhancement by optical structures. The absorption enhancement from Ag nanoparticles was shown in the optical properties of the $\mathrm{Cu}(\mathrm{In}, \mathrm{Ga}) \mathrm{S}_{2}$ solar cell. Now the transfer to the electrical properties is still to be proven.

\section{Conclusions}

The stability during rapid thermal processing of Ag nanoparticles coated with $\mathrm{In}_{2} \mathrm{O}_{3}$ :Mo was confirmed by optical and structural investigations. This is an important step for their integration in ultra-thin glass $/ \operatorname{In}_{2} \mathrm{O}_{3}: \mathrm{Mo} /$ $\mathrm{Cu}(\mathrm{In}, \mathrm{Ga}) \mathrm{S}_{2} / \mathrm{CdS} / \mathrm{i}-\mathrm{ZnO} / \mathrm{n}-\mathrm{ZnO}$ solar cells. Despite a clearly visible optical absorption enhancement above the band-gap energy the proof of enhanced current density of the chalcopyrite solar cell remains challenging. One of the reasons is the fabrication of ultra-thin devices, which however, can allow for an enormous reduction in material consumption. A $6.9 \%$ efficient $\mathrm{Cu}(\mathrm{In}, \mathrm{Ga}) \mathrm{S}_{2}$ solar cell with $500 \mathrm{~nm}$ absorber thickness as mentioned in this paper is a promising starting point for future proof of absorption enhancement by integrating metal nanoparticles in ultra-thin chalcopyrite solar cells as proposed here.

\section{Acknowledgments}

The authours would like to thank B. Bunn for $\mathrm{Cu}(\mathrm{In}, \mathrm{Ga}) \mathrm{S}_{2}$ absorber preparation, C. Kelch for buffer layer deposition, M. Kirsch for ZnO sputtering as well as F. Böhm for optical and electrical characterization and S. Merdes for discussion. 


\section{References}

[1] G. Conibeer, M. Green, R. Corkish, Y. Cho, E.-C. Cho, C.W. Jiang, T. Fangsuwannarak, E. Pink, Y. Huang, T. Puzzer, T. Trupke, B. Richards, A. Shalav, K. Lin, Thin Solid Films 511-512 (2006) 654.

[2] M. Schmid, R. Klenk, M. Ch. Lux-Steiner, Sol. Energy Mat. Sol. Cells $93(2009) 874$.

[3] M. Schmid, R. Klenk, M. Ch. Lux-Steiner, M. Topic, J. Krc, Nanotechnology 22 (2011) 025204.

[4] H. A. Atwater, A. Polman, Nature Materials 9 (2010) 205.

[5] K. Nakayama, K. Tanabe, H. A. Atwater, Appl. Phys. Lett. 93 (2008) 121904.

[6] T. L. Temple, G. D. K. Mahanama, H. S. Reehal, D. M. Bagnall, Solar Energy Materials Solar Cells 93 (2009) 1978.

[7] R. Santbegen, R. Liang, M. Zeman, in: Proc. 35st IEEE Photovolt. Specialists Conf. and Exh., IEEE New York, Hawaii, 2010.

[8] Z. Ouyang, X. Zhao, S. Varlamov, Y. Tao, J. Wong, S. Pillai, Progress in Photovoltaics: Res. and Applications 19 (2011) 917.

[9] M. Westphalen, Solar Energy Materials Solar Cells 61 (2000) 97.

[10] M. Ihara, M. Kanno, S. Inoue, Physica E 42 (2010) 2867.

[11] O. Lundberg, M. Bodegard, J. Malmström, Lars Stolt, Progress in Photovoltaics: Res. and Applications 11 (2003) 77. 
[12] D.L. Young, J. Keane, A. Duda, J. A. M. AbuShama, C. L. Perkins, M. Romero, R. Noufi, Progress in Photovoltaics: Res. and Applications 11 (2003) 535 .

[13] S. Merdes, D. Abou-Ras, R. Mainz, R. Klenk, M. Ch. Lux-Steiner, A. Meeder, H.W. Schock, J. Klaer, Progress in Photovoltaics: Res. and Applications online, doi: 10.1002 (2012).

[14] S. Merdes, M. Schmid, J. Klaer, R. Klenk, J. Krammer, M. Ch. LuxSteiner, in: Proceedings 26nd EPVSEC, Hamburg.

[15] S. Merdes, R. Mainz, J. Klaer, A. Meeder, H. Rodriguez-Alvarez, H. W. Schock, M. Ch. Lux-Steiner, R. Klenk, Solar Energy Materials and Solar Cells 95 (2011) 864 .

[16] R. Mainz, J. Klaer, R. Klenk, N. Papathanasiou, in: Proceedings 22nd EPVSEC, Milano.

[17] H. R. Stuart, D. G. Hall, Appl. Phys. Lett. 73 (1998) 3815.

[18] P. Taneja, P. Ayyub, R. Chandra, Phys. Rev. B 65 (2002) 245412.

[19] K. Ellmer, A. Klein, B. Rech (Eds.), Transparent Conductive Zinc Oxide, Springer, 2008.

[20] Electronic ed, CRC handbook of chemistry and physics, CRC Press, online.

[21] J. D. McBrayer, R. M. Swanson, T. W. Sigmon, J. Electrochem. Soc. 133 (1986) 1242. 
[22] Q. Jiang, S. H. Zhang, J. C. Li, Solid State Communications 130 (2004) 581.

[23] A. Werner, I. Luck, J. Bruns, J. anda K. Siemer, D. Bräunig, Solid State Communications 130 (2004) 581. 